\title{
VEHICLE SPEED AND ROAD LIGHTING LEVEL INFLUENCE ON TRAFFIC SAFETY IN AGGLOMERATIONS AT DARK TIME
}

\author{
Ricardas Butkus, Gediminas Vasiliauskas \\ Aleksandras Stulginskis University, Lithuania \\ ricardas.butkus@asu.lt, gediminas.vasiliauskas@asu.lt
}

\begin{abstract}
The article deals with analysis of application of traffic safety measures in agglomerations at night time. $50 \%$ of fatal traffic injuries happen at night (dark) time or when visibility conditions are insufficient. Pedestrians and bicyclists are involved into approximately $30 \%$ of accidents from the total number. The research and calculations revealed that probability of traffic accidents at day time is approximately $0.000001 \mathrm{vehicles} \cdot \mathrm{km}$, while at dark time it can increase from 15 to more than a hundred percent in case when the asphalt road surface is dry and the driving speed range is from 20 to $50 \mathrm{~km} \cdot \mathrm{h}^{-1}$. In the case of a wet asphalt surface this probability increases from 20 to more than 140 percent correspondingly and in the case the asphalt road surface is covered with ice - from 40 to $>200$ percent. The calculation results show that a safe vehicle stopping distance in nonilluminated roads at dark time will be guaranteed, if the speed of the vehicle does not exceed $40 \mathrm{~km} \cdot \mathrm{h}^{-1}$.
\end{abstract}

Keywords: safety, agglomeration, night, lighting, speed.

\section{Introduction}

High level of accidents on roads is one of the common issues in transportation systems of various countries including Lithuania. The increasing number of vehicles ( 400 for 1000 inhabitants in 2016) is also related to the number of accidents [1]. Unfortunately, the improvement means for the transport safety are not increasing linearly with the economic growth and the increasing number of vehicles. These and other issues usually are the main causes of accidents, which is roughly from 3500 to 4000 yearly over the last five-year period. However, the number of fatal accidents in roads is reducing mostly in Lithuania (in the EU) and it is $37 \%$ over the last 5-year period. However, the number of accidents for 100000 inhabitants is still one of the highest in the EU (83, compared to the average of 51.5 for the entire EU) [2].

The statistical data provided in Figure 1 show the number of fatalities in Lithuania. As it can be seen, the biggest number is the pedestrian fatalities, which consist of approx. 25 percent from the total number.

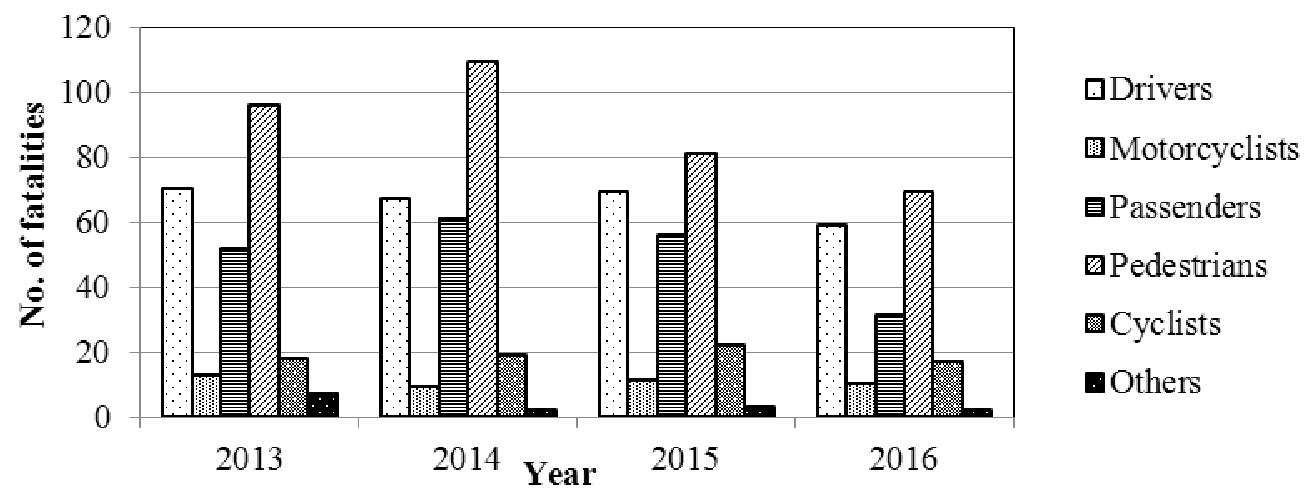

Fig. 1. Tendency of fatalities in road accidents in Lithuania [1]

The data in Figure 2 reveal another fact, that day time has significant influence on accidents. Analysis of the road accident database shows that half of the fatalities are registered in the night time and in pedestrian crossings. Approximately $30 \%$ of all traffic accidents happen in dark time and have worse consequences compared to daytime. $50 \%$ of fatal accidents registered in Lithuania in 2016 were during dark time [2]. These numbers might be reduced, if the road lighting systems were installed, as the lighting quality plays an important role in the visual performance and visual comfort of the road user, which helps keep the driver alert. The results of other studies show that the number of accidents at night time might be reduced using the lighting systems for crossings, roads and other places, as it improves the visibility at dark time [3-5]. However, a combined effect of car headlights 
and road lighting might result in zero contrast in some positions [5], which means that the road lighting level and accident probability are interrelated factors.

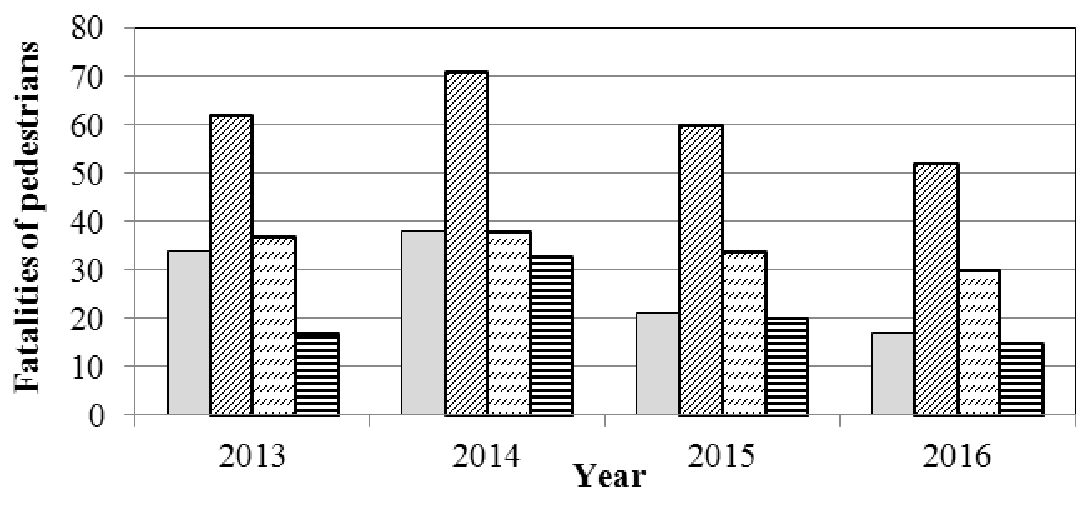

$\square$ Daylight time

DDark daytime

ఐIncluding the road with

lighting

目In pedestrian

crossings

Fig. 2. Tendency of pedestrian fatalities in Lithuania

The abovementioned factors clearly indicate the need of analysing the causes of the accidents and to find the relations between the accident probability, lighting of the road and the driving speed. The speed influence is also crucial, as according to the report approx. $25 \%$ of accidents are being registered in suburban areas (higher speeds), but the number of fatalities is $58 \%$ [1].

The aim of this study was to determine the influence of the driving speed and illumination on the accident probability in agglomerations under various conditions.

\section{Materials and methods}

Large part of the accidents, which have usually crucial consequences, is the crash of the vehicle to pedestrian crossing the street or into any other objects as well as face-to-face crashes. The vehicle driver might avoid such crash, if the vehicle will be stopped before the crossing or any other object. However, this depends strongly on many parameters, such as the driver's reaction time, which might change over the day (night), full stop distance $\left(S_{0}\right)$, driving speed and others. Principal scheme of parameters used in this study and described later in equations and text is given in Figure 1.
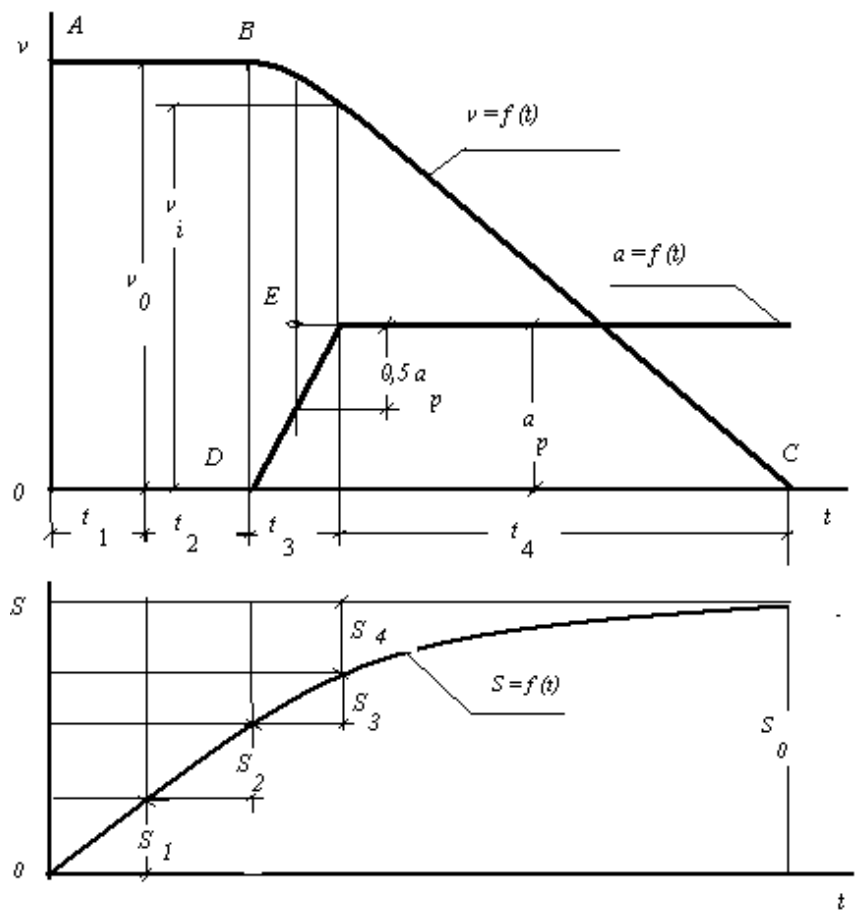

Fig. 2. Dependence of vehicle stopping distance $\left(S_{0}\right)$, slowing $(a)$ and speed $(v)$ over time $(t)[6]$

Full stopping distance $S_{0}$ can be expressed as follows [7]:

$$
S_{0}=S_{1}+S_{2}+S_{3}+S_{4} \text {, }
$$


where $S_{1}$ - distance driven per reaction time $t_{1}$ of the driver;

$S_{2}$ - distance driven per braking delay $t_{2}$;

$S_{3}$ - distance driven per gradual slowing $t_{3}$, while a constant value of slowing $a_{p}$ is reached.

$S_{4}$ - distance per stop time until full stop $t_{4}$.

After expressing the full stop distance $\left(S_{0}\right)$ as the dependence of the driving speed and slowing, we can rewrite the equation 1 as follows:

$$
S_{0}=v_{0}\left(t_{1}+t_{2}\right)+\frac{v_{0}^{2}}{a_{i}}+\frac{v_{\mathrm{i}}^{2}}{2 a_{p}},
$$

where $a_{i}, a_{p}$-slowing down of the vehicle during duration $t_{3}$ and $t_{4}$;

$v_{0}, v_{i}-$ driving speed before braking at the end of $t_{3}$.

Considering that during the duration $t_{3}$ vehicles move constantly slowing and $a_{i}=0,5 a_{p}$, the speed of the vehicle at the end of the period $t_{3}$ will be calculated as follows:

$$
v_{i}=v_{0}-a_{i} t_{3}=v_{0}-0.5 a_{p} t_{3} .
$$

Combining the equation 3 into 2 the full stop duration can be expressed as:

$$
S_{0}=\left(t_{1}+t_{2}+0.5 t_{3}\right) v_{0}+\frac{v_{0}^{2}}{2 a_{p}}-\frac{a_{p} t_{3}^{2}}{8} \text {. }
$$

The last member of the equation can be eliminated, as its significance is relatively small (e. g., for wet asphalt $a_{p} \approx 0.4 \mathrm{~g} \approx 0.4 \cdot 9.81 \approx 3.92 \mathrm{~m} \cdot \mathrm{s}^{-2}$ and $t_{3} \approx 0.6 \mathrm{~s} \mathrm{[6;7],} \mathrm{then} \mathrm{the} \mathrm{value} \mathrm{of} \mathrm{the} \mathrm{last} \mathrm{member} \mathrm{of}$ equation 4 is $\approx 0.176 \mathrm{~m}$ ). The stopping distance is then calculated as follows:

$$
S_{0}=\left(t_{1}+t_{2}+0.5 t_{3}\right) v_{0}+\frac{v_{0}^{2}}{2 a_{p}} .
$$

Member $a_{p}$ can be changed within the expression [6]:

$$
a_{p}=g \cdot \varphi,
$$

Where $g=9.81 \mathrm{~m} \cdot \mathrm{s}^{-2}$;

$\varphi-$ tire and road grip coefficient.

Then equation 5 can be rewritten:

$$
\left.S_{0}=\left(t_{1}+t_{2}+0.5 t_{3}\right) v_{0}+0.051 v_{0}^{2} \varphi^{-1}\right) .
$$

or as follows (when expressing $\mathrm{t}_{1}, t_{2}$ and $t_{3}$ as a full stop time $T$ ):

$$
S_{0}=T v_{0}+0.051 v_{0}^{2} \varphi^{-1} .
$$

Total braking duration $T$ depends on multiple factors, which are determined from accident expertise data [6]. For instance, the value of the parameter $t_{1}$ in the UK is $0.68 \mathrm{~s}$, Russia $0.8 \mathrm{~s}$. When the maximum speed and least distance are calculated, it is recommended to use the value $t_{1}=0.3 \mathrm{~s}[6]$. In the Czech republic the least value of the $t_{1}$ is $0,8 \mathrm{~s}$, when the obstacle is in the zone of good visibility $(5-6)^{\circ}$ and 1.2-1.6s, when the obstacle is outside this region. Duration of the period $t_{2}$ depends on the braking system characteristics and does not depend on the road conditions, mass of the cargo and usually lies within the limits 0.2 to $0.4 \mathrm{~s}$ [6; 7]. Duration $t_{3}$ depends on the brake type, condition of the road and mass of the vehicle. $t_{3}=0.4$ to $0.7 \mathrm{~s}$ on dry asphalt and 0.3 to $0.5 \mathrm{~s}$ on wet asphalt.

\section{Results and discussion}

Theoretical stop time calculations were performed using the equation 7 . The values of the durations were: $t_{1}=0.8 \mathrm{~s}, t_{2}=0.3 \mathrm{~s} ; t_{3}=0.55 \mathrm{~s}$ for dry conditions and $t_{3}=0.4 \mathrm{~s}$ for wet conditions. 
The vehicle tyre/road grip coefficient $\varphi$ for: dry asphalt -0.75 , wet asphalt -0.4 , stamped snow 0.25 and icy road -0.15 [6]. Calculations show that the increase in the vehicle speed from $20 \mathrm{~km} \cdot \mathrm{h}^{-1}$ to $50 \mathrm{~km} \cdot \mathrm{h}^{-1}$ also increases the stopping distance on dry asphalt from 10 to $34 \mathrm{~m}$, on wet asphalt - from 10 to $42 \mathrm{~m}$ (see Fig. 3). These results also show that stopping distances increase much more significantly on snowy and icy roads and can reach 84 metres on icy road at the speed of $50 \mathrm{~km} \cdot \mathrm{h}^{-1}$.

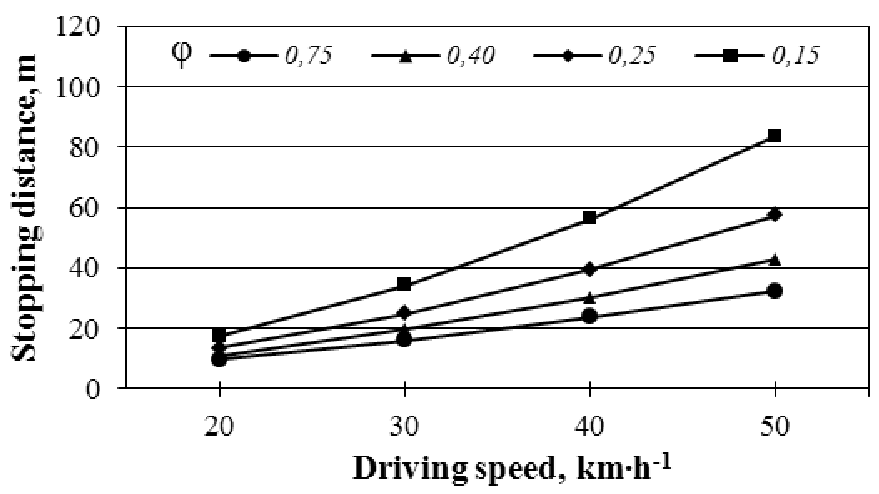

Fig. 3. Dependence of vehicle stopping distance upon speed and griping coefficient

The stopping distance $\left(S_{s}\right)$ to be safe must fulfil the condition $S_{S} \geq S_{0}$ or $S_{S}=S_{0}+\Delta S$ : here $\Delta S-$ distance between the obstacle (cyclist, pedestrian or any other) to the vehicle. Then $S_{0}$ can be calculated as follows:

$$
S_{0}=T v_{0}+0.051 v_{0}^{2} \varphi^{-1}+\Delta S
$$

Using the abovementioned equations the driving speed $v_{0, S}$ can be predicted under various driving and road conditions:

$$
v_{0, S}=9.81\left[T \varphi \pm \sqrt{T^{2} \varphi^{2}+0.2 \varphi\left(S_{s}-\Delta S\right)}\right]
$$

Equation 10 shows that to decrease the stopping distance, the driving speed should be reduced. For instance, if it is required to stop 5 metres from the obstacle on dry asphalt $(\varphi=0.75)$, when $T=1.38 \mathrm{~s}$ and $S_{s}=25 \mathrm{~m}$, safe speed should not exceed $3.7 \mathrm{~m} \cdot \mathrm{s}^{-1}\left(49.3 \mathrm{~km} \cdot \mathrm{h}^{-1}\right)$. If the same requirements apply for wet asphalt $(\varphi=0.4)$ and $T=1.8 \mathrm{~s}-$ safe speed should be maximum $8.31 \mathrm{~m} \cdot \mathrm{s}^{-1}$ i.e. $30 \mathrm{~km} \cdot \mathrm{h}^{-1}$.

Safe driving and stopping depend not only on the human factor, but also on the technical level of the vehicle (auto braking systems, adaptive headlighting systems), road conditions and also the environment. Probability of the accident $P_{A}$ depends on the lighting level of the road [8]:

$$
P_{E}=D_{1} \log _{2}\left(1+D_{2} 5000 / E\right) \text {, }
$$

where $E$-illumination level of the road, lx;

$D_{1}, D_{2}$ - road condition coefficients. $D_{1}=0,4$ and $D_{2}=0,01$ in urban conditions [5].

When the overall headlighting intensity $\Sigma I$ is known (according to the legislation), the distance of the lighted road $(S), E$ illumination level can be calculated [9]:

$$
E=\frac{\sum I}{S^{2}}, 1 \mathrm{x}
$$

Substituting $E$ in equation 11, $P_{E}$ can be calculated as follows:

$$
P_{E}=D_{1} \log _{2}\left(1+D_{2} \frac{5000 S^{2}}{\sum I}\right) .
$$

Total intensity of the vehicle long range lights should be maximum $225000 \mathrm{~cd}$ [9]. Considering that the required lighting should be within the stopping distance $S_{\mathrm{o}}$ the accident probability $P_{E}$ in the dark time can be calculated as follows: 


$$
P_{E}=0.4 \log _{2}\left(1+\frac{50 S_{0}^{2}}{\sum I}\right) .
$$

In reference with Levitin [8], under normal daytime driving conditions, the probability of the accident is equal to 0.000001 vehicle $\cdot \mathrm{km}$. This is the parameter, which includes multiple factor (driving speed, grip coefficient, lighting of the vehicle and the road) influence on the accident. As given in the guidelines by The United Nations Economic Commission for Europe [10] and the working party on Lighting and Light-Signalling subsidiary body of the World Forum for Harmonization of Vehicle Regulations (WP.29), lighting level at the point of the test screen 0.57D$1.14 \mathrm{R}$ (which is the zone of the roadside or sidewalk at a distance of $25 \mathrm{~m}$ from the vehicle) the minimum lighting value of $12 \mathrm{~lx}$ must be reached. Using the equation (12) total lighting of two headlights should exceed $22500 \mathrm{~cd}$ for halogen bulbs. Using equation 13, the probability of the accident was calculated at different speeds. The results show that the probability of accidents might increase from $16\left(20 \mathrm{~km} \cdot \mathrm{h}^{-1}\right)$ to $110 \%\left(70 \mathrm{~km} \cdot \mathrm{h}^{-1}\right)$ driving at night in non-illuminated road with driving lights present (Figure 4).
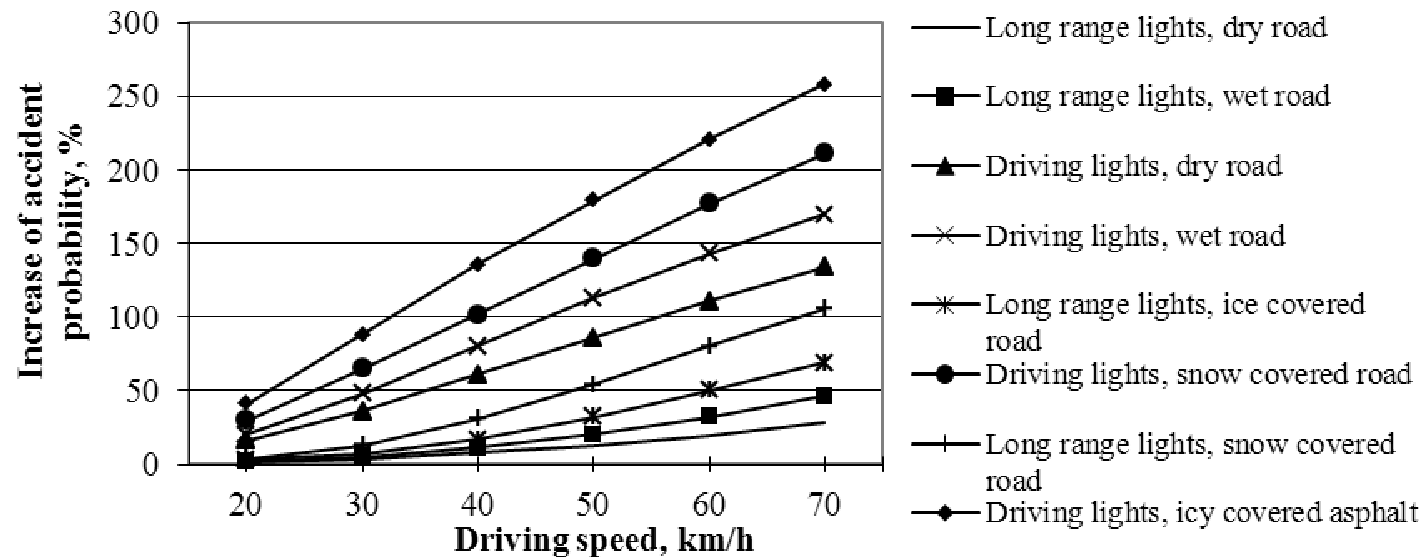

Fig. 4. Dependence probability of traffic accident upon driving speed for various lighting conditions

When the asphalt is wet, the probability might change from 20 to 143 percent, when the road is covered with ice -41 to 220 percent. When halogen lights are used, the probability of an accident decreases significantly. When comparing the accident probability, when road illumination is used, it can be noticed that huge improvement can be reached. If illumination on the road is $9.0 \mathrm{~lx}$, the probability or accidents reduce by half (see Fig. 5).

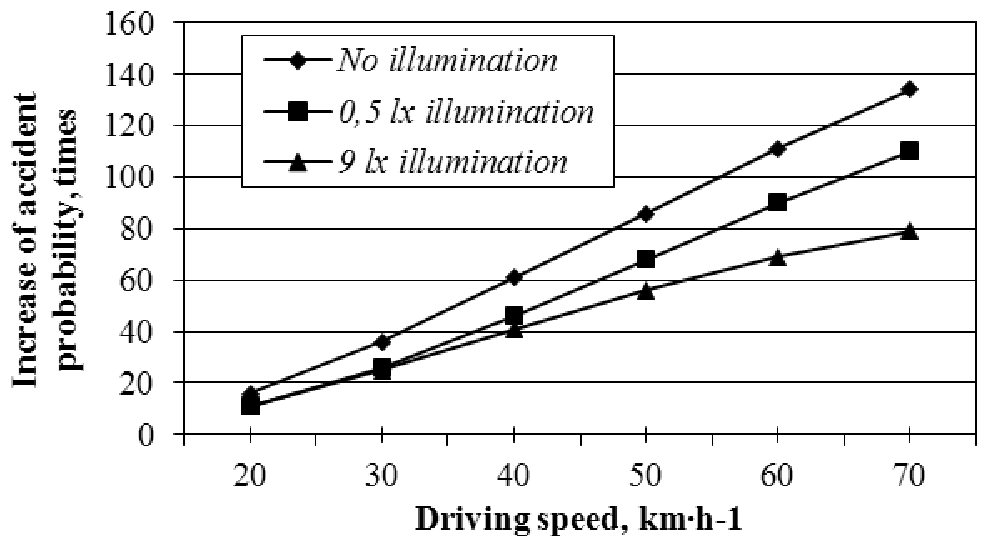

Fig. 5. Dependence probability of traffic accident upon driving speed and illumination of road surface with illuminators

For instance, if the driving speed of the vehicle is $50 \mathrm{~km} \cdot \mathrm{h}^{-1}$ and the driving lights are on, the probability of the accident increases by $\sim 85 \%$, if compared to day time. If the road is additionally 
illuminated with the stationary illuminators with the lighting level of $0.5 \mathrm{~lx}$, the probability of the accident will reduce to $68 \%$ and to $56 \%$, if the illumination level is $9.0 \mathrm{~lx}$. These results are like those obtained by Jackett and Frith [4], where they also found significant influence of illumination on the accident ratio. However, it is clear from these results that the most significant improvement can be achieved by reducing the speed, but not increasing the illumination.

\section{Conclusions}

1. Accident analysis shows that 30 percents of road accidents happen during dark time, while 50 percents of fatalities include pedestrians for the Lithuanian conditions.

2. Calculation results show that a sufficient stopping distance to guarantee safe braking to obstacle is when the vehicle speed is up to $40 \mathrm{~km} \cdot \mathrm{h}^{-1}$ at night time.

3. Probability of the accident might increase by 85 percent during night with driving headlights on, when the road surface is dry, 113 percents, when the surface is wet and 180 percents, when the road is ice covered in comparison with light day time.

4. Additional lighting of the road with the stationary illuminators of 9,0 lx would reduce the accident probability by approximately 50 percent, when the driving speed is $50 \mathrm{~km} \cdot \mathrm{h}^{-1}$.

\section{References}

[1] İskaitinių eismoịvykių statistika Lietuvoje, 2013-2016 m. (Statistic bulletin of road accidents in Lithuania in 2013-2016) (In Lithuanian). [online] [30.01.2018]. Available at: https://lakd.lrv.lt/uploads/lakd/documents/files/eismo_saugumas/statistika/2017/statistika_20132016.pdf

[2] European Commission - Fact Sheet 2016 road safety statistics: What is behind the figures? [online] [21.02.2018]. Available at: http://europa.eu/rapid/press-release_MEMO-17-675_en.htm

[3] Yomak S., Ngaopitakkul A. Optimisation of lighting quality and energy efficiency of LED luminaires in roadway lighting systems on different road surfaces, Sustainable Cities and Society, Vol. 38, 2018, p. 333-347.

[4] Jackett M., Frith W. Quantifying the impact of road lighting on road safety - A New Zealand Study, IATSS Research, Vol. 36, Iss. 2, 2013, pp. 139-145.

[5] Chenani S. B., Maksimainen M., Tetri E., Kosonen I., Luttinen T. The effects of dimmable road lighting: A comparison of measured and perceived visibility, Transportation Research Part F: Traffic Psychology and Behaviour, Volume 43, 2016, pp. 141-156.

[6] Балакин В.Д. Экспертиза дорожно-транспортных происшествий (Expertise of road traffic accidents). Омск, СибАДИ, 2010, 136 p. (In Russian). [online][30.01.2018] Available at: http://www.nntu.ru/sites/default/files/file/svedeniya-ob-ngtu/its/obrazovanie/och/bak/190600.62ettmikm/as/metod/Metod_oae_as_190600.62ettmikm_edtp_up.pdf

[7] Liutkevičius R., Eičinas J., Butkus R. Eismos augumo pagrindai (Basics of road safety) Kaunas: Akademija, 1997. 79 p. (In Lithuanian)

[8] Левитин К. М. Эффективность освещения и световой сигнализации автотранспортных средств (Lighting and light-Signalling effectiveness in autotransport) Moscow: Энергоатомиздат, 1991. 240 p. (In Russian).

[9] Commission Directive 91/663/EEC of 10 December 1991 adapting to technical progress Council Directive 76/756/EEC relating to the installation of lighting and light-signalling devices of motor vehicles and their trailers - Official Journal of the European Union, L 366, 31/12/1991, p. 00170054.

[10] World Forum for Harmonisation of Vehicle Regulations (WP.29). Rationale of harmonized passing (dipped) beam pattern. TRANS/WP.29/GRE/2001/2818, 2001. 11 p. 